NIST Technical Note 2174

\title{
Response Time Impact of Smoke Alarms
}

Dr. Stanley Gilbert

Tom Cleary

Paul Reneke Richard Peacock

Dr. David Butry

This publication is available free of charge from: https://doi.org/10.6028/NIST.TN.2174

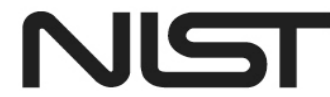




\title{
NIST Technical Note 2174
}

\section{Response Time Impact of Smoke Alarms}

\author{
Dr. Stanley Gilbert \\ Dr. David Butry \\ Office of Applied Economics \\ Engineering Laboratory
}

Tom Cleary

Paul Reneke

Richard Peacock

Fire Research Division

Engineering Laboratory

This publication is available free of charge from:

https://doi.org/10.6028/NIST.TN.2174

September 2021

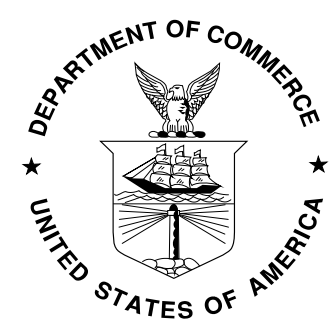

U.S. Department of Commerce Gina M. Raimondo, Secretary

National Institute of Standards and Technology James K. Olthoff, Performing the Non-Exclusive Functions and Duties of the Under Secretary of Commerce for Standards and Technology \& Director, National Institute of Standards and Technology 
Certain commercial entities, equipment, or materials may be identified in this document in order to describe an experimental procedure or concept adequately. Such identification is not intended to imply recommendation or endorsement by the National Institute of Standards and Technology, nor is it intended to imply that the entities, materials, or equipment are necessarily the best available for the purpose.

National Institute of Standards and Technology Technical Note 2714 Natl. Inst. Stand. Technol. Tech. Note 2174, 31 pages (September 2021) CODEN: NTNOEF

This publication is available free of charge from: https://doi.org/10.6028/NIST.TN.2174 


\begin{abstract}
It can be assumed that smoke alarms reduce reported fires and casualties by reducing on average the amount of time it takes to detect a fire. This paper sets out to determine by how much that detection time is reduced. It does so by comparing the effect of smoke-alarm presents (and time of day) to the effect of fire-department travel time using data from the National Fire Incident Reporting System. On average, smoke alarms reduce reporting time by $19.2( \pm 0.016)$ minutes. This is comparable to the average time delay from having a fire at night. If smoke alarms are present, having a fire at night (between the hours of 11 and 6) adds $18.1( \pm 0.013)$ minutes, and without an alarm, having a fire at night adds on average 20.5 ( \pm $0.024)$. Smoke alarms are more effective at night, saving $2.4( \pm 0.016)$ minutes more at night than during the day.
\end{abstract}

\title{
Key words
}

Fire; Home Fires; Smoke Alarms; Response Time. 


\section{Table of Contents}

1. Introduction ............................................................................................................................. 1

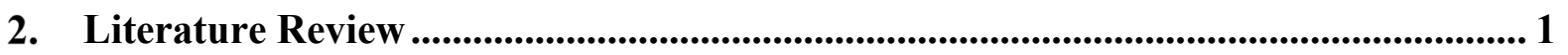

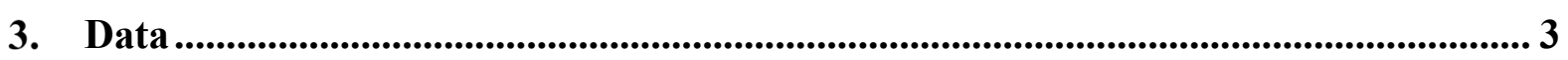

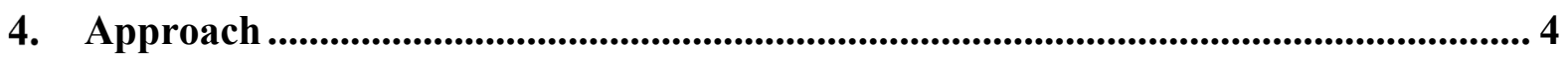

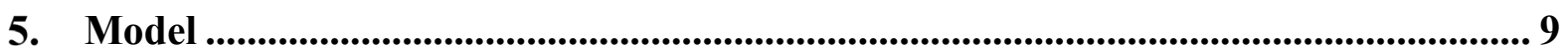

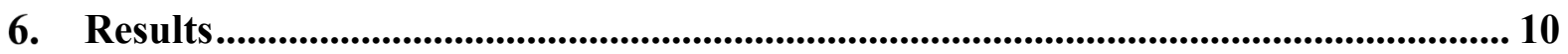

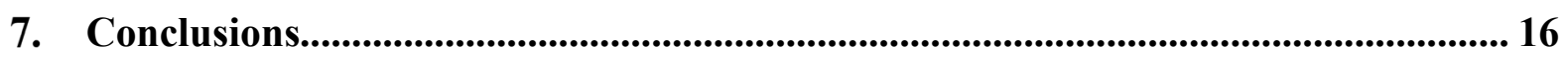

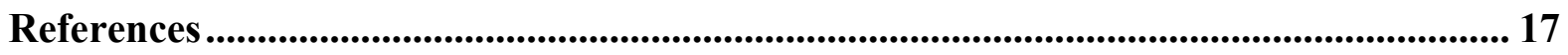

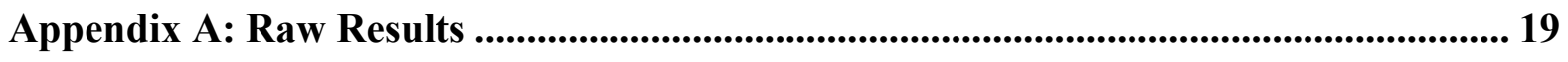

Appendix B: Abstract Model ................................................................................................... 22

Appendix C: Maximum Likelihood Model ................................................................................ 24

Appendix D: Smoke Alarms and Time of Day ............................................................................ 25

\section{List of Tables}

Table 1: Model Results. Offsets are expressed in minutes, alpha is expressed in probability, and 'beta' represents the inverse scale parameter. Standard errors are listed in parentheses

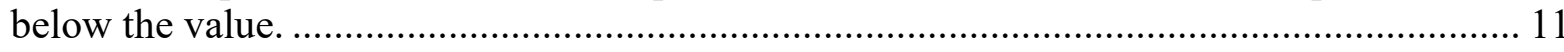
Table 2: Summary of the effect of time of day and smoke alarm presence on reporting delay in minutes. The baseline is daytime with smoke alarms present. ........................................... 15

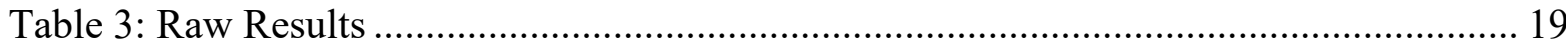

\section{List of Figures}

Fig. 1: The basic model.

Fig. 2: This illustrates the basic approach. The red curve represents the "standard" curve, while the green curve represents a different set of circumstances. The offset is what is estimated.

Fig. 3: Probability of growth beyond the room of origin as a function of fire department response time.

Fig. 4: Percent of fire-classification information types unknown as a function of fire spread. 8

Fig. 5: Reporting time offsets in minutes by time of day and room of fire origin. Left shows offsets without smoke alarms. Right shows the improvement smoke alarms bring. 14 Fig. 6: Probability that a fire will go beyond the room of origin versus delayed fire department travel time. 16

Fig. 7: Reporting rate for smoke alarms at fires by time of day. 25 


\section{Introduction}

Smoke alarms have been in widespread use in the United States since the mid-1970s. Over that time smoke alarm usage has increased from less than $25 \%$ to more than $90 \%$ [1]. It is widely understood that they have reduced the severity of the fire problem [1] [2] [3]. Nevertheless, efforts to quantify the effect of smoke alarms on the number of reported fires and fire casualties have been desultory.

Further very little effort has been devoted to understanding the mechanisms by which smoke alarms produce their beneficial effects. Presumably, smoke alarms result in detection of fires on average earlier than they would be detected if no smoke alarms are present. The earlier detection gives more time for evacuation and enables earlier extinguishment of fires, resulting in lower casualties and less damage. However, there is no empirical evidence to indicate how much time smoke alarms gain in terms of fire detection.

The purpose of this study is to better understand how smoke alarms improve fire outcomes. It specifically sets out to estimate the impact that smoke alarms have on reporting time. Reporting time is the amount of time between ignition of a fire and the time when it is reported to the fire department. This study sets out to identify the amount of time, on average, that the presence of smoke alarms reduces reporting time.

\section{Literature Review}

Several studies (e.g., [1] [2], and [3]) have found that smoke alarms are important for reducing fire risk. A higher percentage of fires are reported to the fire department in homes without smoke alarms than in homes with them. Ahrens [1] reports that "in 2009-2013, more than one-third (35\%) of reported home fires occurred in properties with either no smoke alarms or no working smoke alarms." Such homes constitute less than $5 \%$ of all households [1]. Rohde et al. [2] observed that "while smoke alarms alone cannot combat household fires, a growing body of empirical evidence indicates that they are an effective tool in reducing the number of associated deaths and injuries." They conducted a meta-analysis of studies that looked at the effectiveness of smoke alarms and concluded that smoke alarms reduce death rates in households by $50 \%$.

Gilbert [3] sets out to quantify the effect of smoke alarms on the rate of domestic fires and fire death rates. He found that "the installation of smoke alarms in homes without them reduces the expected number of fires reported from a (formerly) non-smoke-alarm residence by a factor of 3.5 to 5 " He also found that fires in homes without smoke alarms are less deadly on a per-fire basis. He speculated that the reason is that smoke alarms tend to result in the extinguishment of the less dangerous fires. Even so, he estimated that installation of smoke alarms reduces the overall death rate by a factor of 2.5 to 3.5 because the total number of fires in such homes was much smaller.

Greene and Andres [4] described results of the Consumer Product Safety Commission's third national telephone survey of unreported and non-fire department-attended residential fires. The survey found there were 7.4 million residential fires annually, which is a rate of 6.6 
residential structure fires per 100 households. Only about $3.4 \%$ of fires were attended by the fire department.

Hall [5] did an analysis of 5 years of fire incidence data. Using two different methods he analyzed how deaths and injuries would be reduced if the occupants had more time.

According to his analysis, deaths could be cut by as much as half, and injuries could be cut by two-thirds. However, these results are using some potentially optimistic assumptions.

There have been a number of studies that looked at human behavior in fire. Most of those have looked at commercial and industrial settings, but a number of them have looked specifically at the residential environment.

Wood [6] conducted one of the first studies that looked at human behavior in a fire. The study looked at a collection of data from the United Kingdom that focused on fires with individuals involved. A majority of the data came from dwellings. Wood looked at the first three actions that each person took. In order of most frequent the first three were: "some firefighting action," "contact fire brigade," and "investigate fire." "Evacuated oneself" from building was the sixth most frequent action. He then categorized the actions based on the individual's familiarity with the building layout, perception of the seriousness of the fire, the degree of training, and previous experience in a fire. This allowed for a breakdown in the general behavior, how evacuations occurred, and movement through the smoke. Gender differences were also considered due to the noticeable differences in actions between male and females. One such difference was how men and women noticed a fire. Women were more likely to concluded that a fire was occurring based on seeing smoke. Men, however, more often had to see flames to be convinced of a fire.

Bryan [7] designed a study based on Wood's [6] that focused on fires that occurred in the metropolitan Washington, D.C/Baltimore, MD area. The majority of the fires occurred within dwellings and apartments [7]. Bryan started by looking at how the participant population became aware of the fire, and then looked at the gender distribution of this data. As Wood did, Bryan also looked at the first three actions that were completed. The actions were analyzed based on gender distribution, training, and previous fire experience. Comparing his results with Wood's [6], he found that British populations were more likely to fight the fire as their first action, whereas Americans were more likely to notify others. Also, Americans were more likely to present behaviors related to evacuation, and the British were more likely to reenter a building.

Thompson et al. [8] reviewed the literature on human behavior in dwelling fires. Unlike fires in commercial and public spaces, people investigate cues promptly. They engage in numerous activities in the "pre-movement" or "response" phase. Often, they will "attempt to tackle or mitigate the fire" and may never arrive at the "movement" or "evacuation movement" phase; reentry is common.

There have been a number of case studies looking at behavior in specific incidents.

Thompson and Wales [9] did post-incident interviews of people who had been injured in accidental dwelling fires in Kent, UK. They focused on the motivations and behaviors of the individuals the fire. Out of the ten interviews that were conducted, $50 \%$ did not realize that a fire was occurring in their home even after hearing an alarm or seeing smoke. Eight of ten 
interviewees went to investigate the cues to determine what was happening. Seven of ten attempted to fight or mitigate the fire. Several interviewees expressed what the authors termed "shame and embarrassment" at calling the fire service. The authors suggested that this feeling might cause some people to delay calling in the fire department.

Pauls [10] analyzed two different fires that both resulted in fatalities. The analysis shows a set of times that indicate when various actions were thought to have occurred during both fires. The first fire occurred in a 21-story apartment building on the seventh floor. It started as a smoldering fire that took the occupant of the apartment between $15 \mathrm{~min}$ to $30 \mathrm{~min}$ to notice. The occupant attempted to extinguish the fire. However, they soon realized it would not be possible and fled the apartment. Shortly after, the apartment experienced flashover, and the building alarm started to sound. The second fire occurred in a two-story apartment and was caused by ashes from an ashtray being dumped into the trash. It started on the 1st floor of the building. This fire had over 2 hours to build before a burning smell was detected by the occupants in the apartment where the fatality occurred. The male occupant went to go and investigate the 1st-floor apartment. While investigating, he left the apartment door open which caused smoke to start building up in the stairway. The female occupant was unable to evacuate due to the amount of smoke. She died from carbon monoxide poisoning from smoke inhalation.

\section{Data}

Data are from National Fire Incident Reporting System (NFIRS). All home structure fires that occur after 2004 where the structure-fire module was filled out are selected for this study. Note that this excludes many-possibly most-confined-to-object fires. The 'arrival' and 'alarm' fields are used to calculate a fire-department travel time value in minutes. Alarm time is used to determine the hour of day for the fire. Any records where time of day, travel time or degree of fire spread cannot be determined from the data are excluded. Detroit is excluded because past experience suggests that reporting is significantly different from other departments.

The NFIRS is a reporting system used by fire departments nationwide to report on their activities. The system is maintained by the U.S. Department of Homeland Security and the U.S. Fire Administration and is designed to capture all activities engaged in by a fire department, including fires, emergency medical service (EMS) and community outreach. The system is voluntary at the national level, so some departments do not use the system or report data from it.

The NFIRS system records the time, date and location of all incidents, the type of the incident (e.g., fire, EMS call, hazardous materials incident, service call, etc.), property use, equipment and personnel on the call, number type and severity of casualties, actions taken, and a host of other data. For fires specifically, NFIRS collects information in its "structure fire module" on the size of the fire, room of origin, heat source, item first ignited, human and other factors contributing to ignition, presence and effectiveness of detection and automatic suppression equipment among other data. However, the structure fire module is not required to be filled out for fires that are confined to the object of origin.

Data for NFIRS is filled out by firefighters at the scene, so the information it contains is typically limited to the information a firefighter at the scene would have. For example, fire 
deaths are defined as any fire casualties resulting in death within one year. However, it seems likely that follow-up on casualties is sporadic at best. Often data that is not required is left unentered. For example, extent of fire spread is recorded for only about $30 \%$ of fires. Other systematic problems can occur. For example, a number of large departments report in excess of $80 \%$ of the fires they respond to are confined fires (the nationwide average is less than $40 \%$ ). Nevertheless, while NFIRS has known reporting problems, it is still the best data set available for understanding the nature and extent of the urban fire problem in the United States.

\section{Approach}

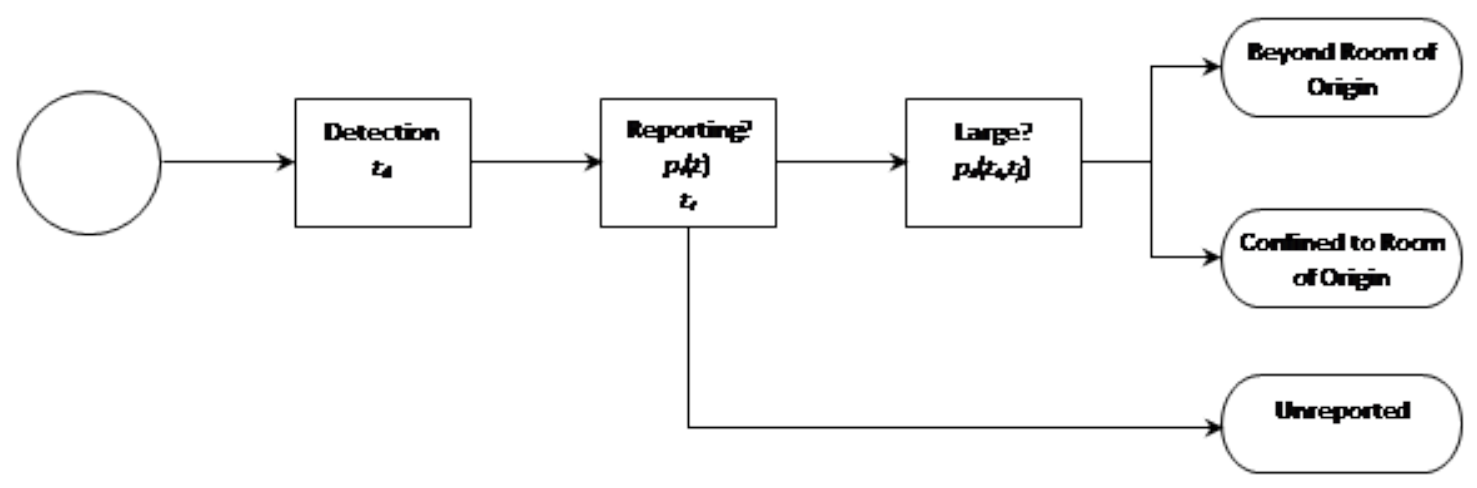

Fig. 1: The basic model depicting the fire ignition and reporting process used for this analysis.

The basic model is shown in Fig. 1. After ignition, the fire is detected after a time $t_{d}$. Size $s$ of the fire at time of detection will be a function of $t_{d}$. Whether a fire is reported to the fire department, in turn, depends on the size at detection. If the size is smaller than some cutoff value, which will depend on the person detecting the fire, then the fire is extinguished and remains unreported. Otherwise the fire is reported to the fire department. Final fire size, which here is limited to whether the fire is confined to the room of origin or spreads beyond the room of origin, depends on the time to detection and the fire-department response time.

The approach is illustrated in Fig. 2. The idea is to build a 'Time Delay v. Fire' growth curve using fire department response time. The curve is built for a "standard" set of circumstances, and separate curves are built for any other circumstances that can be expected to impact reporting time. Examples include time of day and the presence of smoke alarms. The amount of time that the curve has to be shifted to match the standard curve represents the relative amount of time that the circumstance represents in terms of reporting time.

For example, the red curve in Fig. 2 could represent the probability a fire goes beyond the room of origin versus fire-department travel time for fires occurring at 6:00 pm where smoke alarms are present, and the green curve could represent the same curve for fires occurring at 7:00 pm where smoke alarms are absent. The horizontal distance between the curves (here, three minutes) is what is measured using the approach here. 


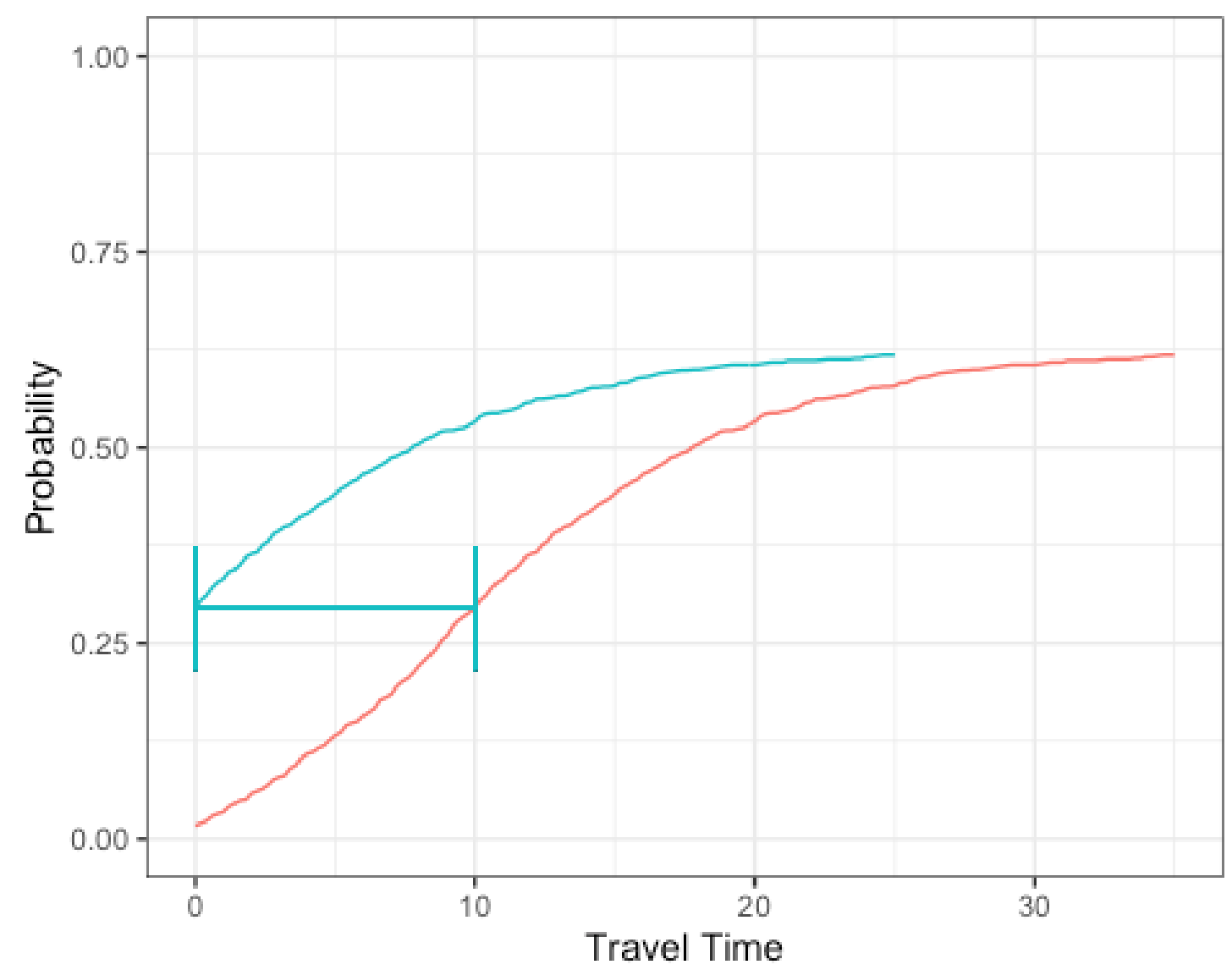

Fig. 2: This illustrates the basic approach to measure the impact of smoke alarms. The red curve represents the "standard" curve, while the green curve represents a different set of circumstances. The offset is what is estimated.

Note that by working with NFIRS, we are estimating this conditional on the fire being reported and the fire-incident table filled out. The main impact of that limitation is that reporting delay is not directly comparable to fire department response time in terms of fire severity. The problem lies in the fact that most fires are not reported to the fire department. A delay in detection and reporting not only allows fires to grow-the effect that is directly comparable to fire-department response time-it also increases the number of fires that are reported to the fire department. Essentially, some fires that previously were small enough to be extinguished without being reported to the fire department have now grown too big and will be reported.

How similar reporting delay will be to response time will depend on how aggressive and numerous the additional fires are relative to the initial set. Appendix B develops this analysis more fully. Initially the new fires were smaller than the ones that were reported. It is expected that on average fires that start out smaller will continue to be smaller. If that is the case, and since delay is estimated by comparing the new fire sizes to the index fire sizes, the time delay estimated using this approach will be underestimated. 
The delay measured in this analysis is best understood as a reporting delay. To see how reporting delay differs from detection delay consider the effect of a fire at 3:00 am versus one at 8:00 pm. It is well known that people often engage in many different tasks after detecting a fire. In fact, calling the fire department is typically one of the last tasks undertaken. Consider a fire and conditions where the occupants would "immediately" leave and report the fire. At 8:00 pm this largely consists of collecting people and a few important belongings (like cell phones) and leaving the house. That process would likely be completed fairly quickly. At 3:00 am, however, that process involves waking everyone up, possibly getting dressed for the weather (finding coats, shoes, etc.), collecting important belongings (the aforementioned cell phones), and leaving the house. Even assuming detection time is identical, reporting time for the 3:00 am fire will be significantly longer.

When estimating the effect of smoke alarms, it is necessary to consider the issue of casualties because the reporting rate for alarms differs based on whether there were casualties. That in and of itself would not be an issue, except that fires with casualties, all else equal, are likely to be more aggressive than fires without casualties. If that is so, then aggressive fires are oversampled in terms of alarm state, which would bias the results when looking at the impact of alarms. To address this, fires are weighted based on the presence of casualties whenever smoke alarms are included in the estimation.

The analyses below is restricted to fires where response time is between one minute and 20 minutes.

Fig. 3 shows the probability of a fire growing beyond room of origin as a function of firedepartment response time (in minutes). The curve should be monotonically increasing with time. What the figure shows is the probability increasing for response times greater than five minutes but decreasing with time for response times shorter than that. The figure forms a 'hook' where it should be monotonically increasing. 


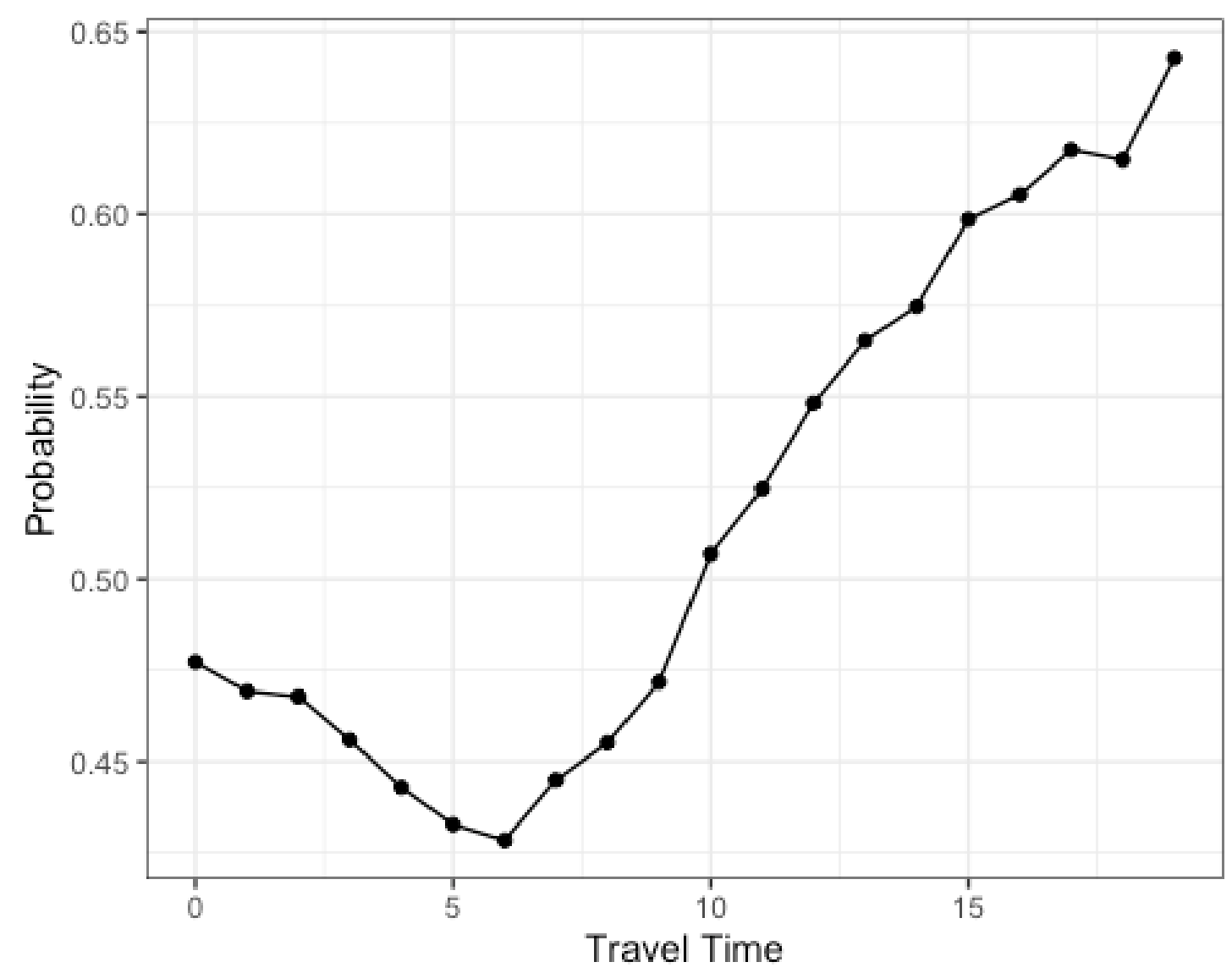

Fig. 3: Probability of growth beyond the room of origin as a function of fire department response time.

One explanation for the hook is that it is the product of reporting 'errors.' There will be an underlying distribution of response times, and very short response times will be rare. A certain percentage of those reporting times will be reported in error. For simplicity, assume the error rate is independent of actual response time. Then the expected outcome for any response time reported in error will be the average over all fires.

Reported values for 'errors,' however, will not uniformly distributed. Short response time will be more likely for those 'error' values than long ones. Standards for fire-department response establish standards for response time that fire departments are expected to meet. So, if a department is going to make an error in reporting response time, there is an incentive to make an 'error' that makes the response look quicker rather than slower.

Therefore, for any response time, the measured outcome will be the weighted average of the actual outcome for that response time and the 'error' outcome. For very short response times the 'error' values will outweigh the actual values and you will get the hook.

The problem is addressed here by excluding the times where 'error' reports likely outweigh the actual values-specifically fire-department response times less than five minutes. 


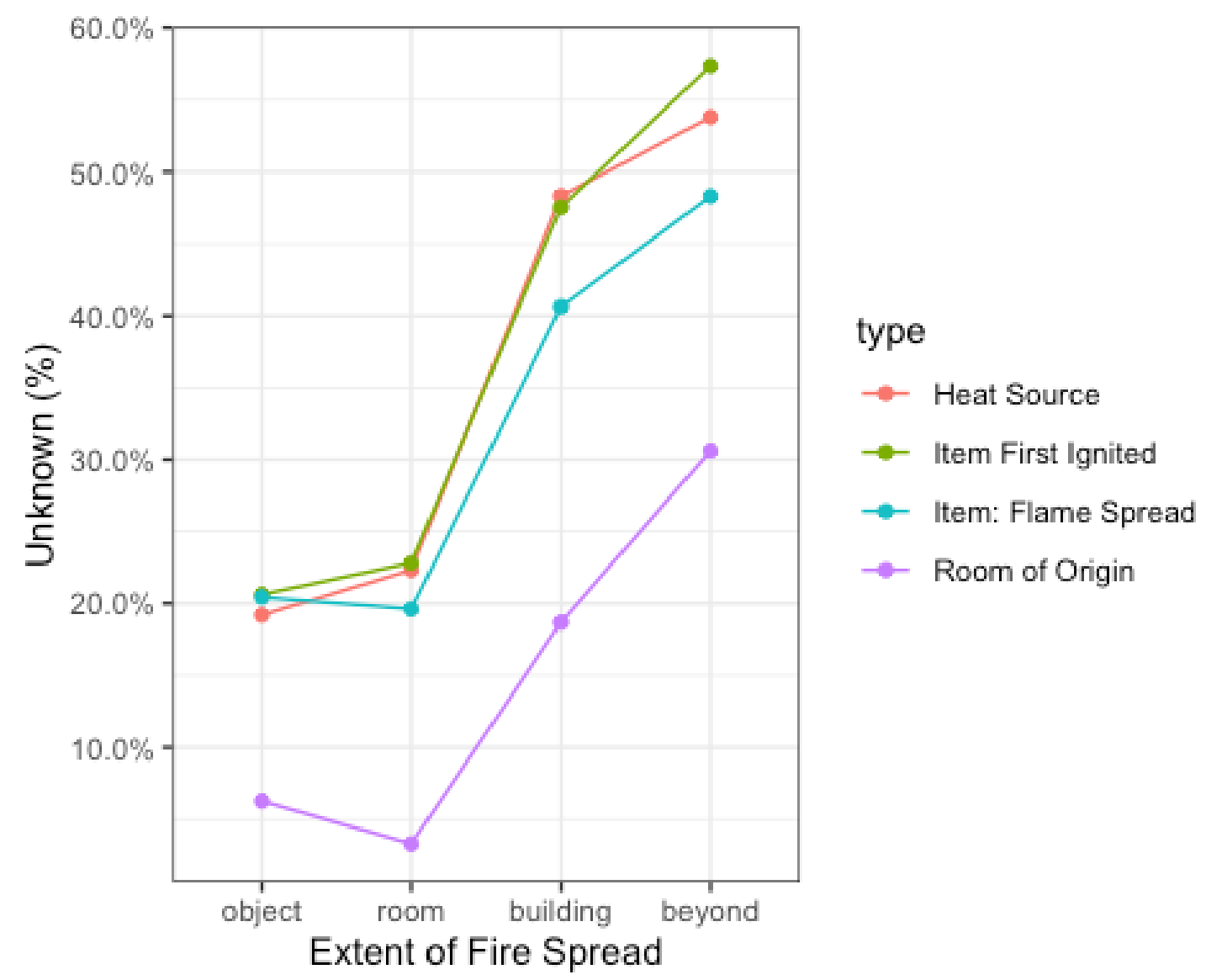

Fig. 4: Percent of fire-classification information types reported as 'unknown' shown as a function of fire spread.

It is expected that the proportions of different fire types will vary by time of day. Since different fire types will vary in their severity, failure to correct for fire type would alter the results of this study.

For various fields giving information about the fire within NFIRS, Fig. 4 shows the percent of entries that are unknown as a function of fire spread. For heat source, item first ignited, and item most contributing to flame spread the percent of entries unknown increase dramatically as the extent of flame spread gets larger. For large fires, the percent unknown is in the range of $50 \%$ for those fields. That is not unreasonable considering that it is more likely that evidence will have been destroyed in larger more severe fires.

However, that presents a serious problem with using those fields to identify fire types for this study. We expect the mix of fire types-and the associated mix of ex ante severities-to vary with time of day. We need to correct for that to get an accurate estimate of the impact of time of day and smoke alarms on delay time. By using these characteristics, we screen out the most severe-and most aggressive-fires and thus bias the results. Further, the firecategorization itself becomes dependent on time of day-since the more severe fires will tend to occur at night-introducing an additional bias into the results. 
Room of origin presents the least severe problems in this regard, so it is used in this study as indicator of fire type.

\section{Model}

The model used assumes that all fires follow a similar profile-at least in probability. That is, there exists a single function, $F$ (time), increasing in time, which represents the probability that a fire goes beyond the room of origin at time $t$ after the time of ignition. Some proportion of those fires will never go beyond the room of origin, even if the fire department never arrives. The difference between times of day is exclusively due to differences in the time at which a fire is reported.

This makes it possible to use the different response-time-versus-size profiles to obtain information on different portions of the response curve. So, the $6 \mathrm{pm}$ profile would give information on the response curve for shorter response times while the 3 am profile would provide information on the response curve for longer response times.

Basic model assumptions:

- All fires follow a constant profile in probability. That is, there is a single responsetime-versus-probability curve for all fires regardless of time of day.

- The effect of time of day is exclusively in terms of the delay in reporting the fire to the fire department.

The formal model is defined as follows:

$i$ is the index over the set of fires

$h$ is the index over the set of hours in the day.

$k$ is the index over the set of fire types.

$y_{i}$ is an indicator identifying whether fire $i$ went beyond the room of origin.

$h_{i}$ is the hour when the alarm went out for fire $i$. This is used as a proxy for time of ignition.

$k_{i}$ is the fire type for fire $i$.

$F$ is a cumulative probability distribution. The cumulative normal probability function is used below, but logistic, as well as others, are possible.

$\alpha$ is a parameter that represents the proportion of reported fires that have the potential to go beyond the room of origin. Or, to put it differently, $1-\alpha$ represents the proportion of reported fires that would never go beyond the room of origin, even if the fire department never arrived.

$\zeta_{h}$ is a vector of parameters representing the relative time at which the fire is reported for each hour $h$ during the day. So, in the results below, $\zeta_{0}$ is about 0 and $\zeta_{3}$ is about 4.5. So, fires that occur during the 3 am hour are reported on average 4.5 minutes later (relative to time of ignition) that fires that occur at midnight. 
$\sigma_{k}$ is the scale parameter for each fire type.

$a_{i}$ is a dummy variable indicating if smoke alarms were present.

$\delta_{h}$ is a vector of parameters representing the additional time at which a fire is reported for each hour $h$ during the day if a smoke alarm is absent.

Then let

$$
u_{i}=\frac{t_{i}+\zeta_{h_{i}}+\left(1-a_{i}\right) \delta_{h_{i}}}{\sigma_{k_{i}}}
$$

and

$$
P\left\{y_{i}=1\right\}=\alpha F\left(u_{i}\right) .
$$

The variables defined above are easily interpretable. However, to simplify estimation the model needs to be linearized. The variables used in the linearized model are less easily interpretable, but the easily interpretable variables can be back-calculated after the estimation is complete. The revised (linearized) model is:

$$
u_{i}=\beta_{k_{i}} t_{i}+\hat{\zeta}_{h_{i} k_{i}}+\left(1-a_{i}\right) \hat{\delta}_{h_{i} k_{i}}
$$

where $\beta_{k_{i}}=\frac{1}{\sigma_{k_{i}}}$ is the inverse scale parameter, and $\hat{\zeta}_{h_{i} k_{i}}=\frac{\zeta_{h_{i}}}{\sigma_{k_{i}}}$ and $\hat{\delta}_{h_{i} k_{i}}=\frac{\delta_{h_{i}}}{\sigma_{k_{i}}}$ are scaled offsets. The model is estimated using maximum likelihood. When presenting the results below, the original $\zeta_{h_{i}}$ and $\delta_{h_{i}}$ values will be presented, but the expression above is what is estimated. In addition, separate models for each room of origin are estimated.

As discussed above, because all response curves demonstrate a hook pattern, those response times less than 5 minutes are filtered out.

\section{Results}

Table 1 below expresses the results in minutes for the reporting time offsets for all fires. (Raw results are in the appendix). The $\alpha$ value above is estimated as the logistic of $\alpha$, and below that is transformed back to raw $\alpha$. The beta term is the inverse scale parameter. Table 2 summarized the effects of smoke alarms.

The estimated values of $\zeta$ range beween -11 and 19, which implies a time difference in reporting fires of 29.3 minutes between the shortest and longest time till reporting.

Time-of-day savings for smoke alarms could not be estimated for living room fires or bedroom fires. The models for those rooms were estimated using a constant savings for smoke alarms.

Fig. 5.a plots the reporting time offsets by time of day for the case where there are no smoke alarms. The figure includes relative offsets for all fires, and also for several rooms. Note that since the time-of-day offsets are only defined up to an additive constant, they have been adjusted in the figure so that noon is zero. 
Table 1: Model Results. Reporting time offsets are expressed in minutes, 'alpha' is expressed in probability, and 'beta' represents the inverse scale parameter. Standard errors are listed in parentheses below the value. Hour of day is relative to midnight ('hour0').

All Fires Kitchen Living Room Bedroom

\begin{tabular}{lcccc}
\hline alpha & 0.94 & 0.93 & 0.93 & 0.95 \\
& $(0.02)$ & $(0.13)$ & $(0.06)$ & $(0.05)$ \\
beta & 0.02 & 0.01 & 0.01 & 0.01 \\
& $(0.00)$ & $(0.00)$ & $(0.00)$ & $(0.00)$ \\
hour0 & 9.89 & -28.34 & 25.78 & -1.73 \\
& $(1.52)$ & $(8.00)$ & $(10.67)$ & $(11.68)$ \\
hour1 & 13.60 & -20.60 & 35.91 & 14.38 \\
& $(1.56)$ & $(8.14)$ & $(12.30)$ & $(15.04)$ \\
hour2 & 16.26 & -12.07 & 41.19 & 33.18 \\
& $(1.64)$ & $(8.39)$ & $(12.96)$ & $(22.48)$ \\
hour3 & 18.59 & -12.00 & 55.18 & 36.97 \\
& $(1.71)$ & $(8.28)$ & $(16.16)$ & $(23.42)$ \\
hour4 & 18.35 & -12.76 & 37.64 & 39.85 \\
& $(1.70)$ & $(8.39)$ & $(12.70)$ & $(25.33)$ \\
hour5 & 13.45 & -17.41 & 40.45 & 21.35 \\
& $(1.64)$ & $(8.49)$ & $(13.36)$ & $(17.55)$ \\
hour6 & 5.47 & -27.01 & 16.34 & -0.00 \\
& $(1.47)$ & $(8.20)$ & $(9.58)$ & $(11.92)$ \\
hour7 & -3.23 & -37.80 & 12.26 & -13.35 \\
& $(1.40)$ & $(8.30)$ & $(9.22)$ & $(11.83)$ \\
hour8 & -6.47 & -36.87 & 6.88 & -19.18 \\
& $(1.39)$ & $(8.12)$ & $(8.75)$ & $(12.51)$ \\
hour9 & -8.73 & -47.57 & 8.59 & -19.06 \\
& $(1.41)$ & $(8.37)$ & $(8.82)$ & $(12.36)$ \\
hour10 & -9.19 & -54.71 & 6.17 & -6.43 \\
& $(1.40)$ & $(8.49)$ & $(8.82)$ & $(11.50)$ \\
hour11 & -7.94 & -49.43 & 2.70 & -16.33 \\
& $(1.40)$ & $(8.33)$ & $(8.59)$ & $(12.06)$ \\
hour12 & -7.72 & -56.16 & 10.79 & -32.96 \\
& $(1.37)$ & $(8.47)$ & $(8.88)$ & $(15.71)$ \\
hour13 & -6.22 & -47.43 & 2.17 & -30.04 \\
& $(1.37)$ & $(8.20)$ & $(8.32)$ & $(14.42)$ \\
hour14 & -8.00 & -54.95 & 7.33 & -25.43 \\
& $(1.37)$ & $(8.44)$ & $(8.63)$ & $(13.66)$ \\
hour15 & -7.95 & -51.99 & -9.07 & -38.32 \\
& $(1.37)$ & $(8.34)$ & $(8.54)$ & $(17.40)$ \\
hour16 & -9.05 & -63.24 & -6.04 & -35.31 \\
& & & & \\
& & &
\end{tabular}


All Fires Kitchen Living Room Bedroom

\begin{tabular}{|c|c|c|c|c|}
\hline & $(1.40)$ & $(8.75)$ & $(8.37)$ & $(16.25)$ \\
\hline \multirow[t]{2}{*}{ hour17 } & -9.14 & -60.29 & -7.85 & -49.34 \\
\hline & $(1.38)$ & $(8.73)$ & $(8.38)$ & (21.71) \\
\hline \multirow[t]{2}{*}{ hour18 } & -10.83 & -57.77 & -21.45 & -40.48 \\
\hline & $(1.37)$ & $(8.42)$ & $(9.69)$ & (18.43) \\
\hline \multirow[t]{2}{*}{ hour19 } & -9.03 & -59.77 & -7.83 & -28.95 \\
\hline & $(1.38)$ & $(8.61)$ & $(8.50)$ & (14.31) \\
\hline \multirow[t]{2}{*}{ hour20 } & -5.10 & -52.48 & -10.10 & -30.69 \\
\hline & $(1.37)$ & $(8.32)$ & $(8.51)$ & (15.26) \\
\hline \multirow[t]{2}{*}{ hour21 } & -3.03 & -47.57 & -0.24 & -29.93 \\
\hline & $(1.40)$ & $(8.28)$ & $(8.27)$ & (15.32) \\
\hline \multirow[t]{2}{*}{ hour22 } & 0.26 & -39.83 & 8.99 & -16.97 \\
\hline & $(1.42)$ & $(8.10)$ & $(8.71)$ & (11.64) \\
\hline \multirow[t]{2}{*}{ hour23 } & 6.00 & -40.78 & 26.75 & -11.16 \\
\hline & $(1.46)$ & $(8.19)$ & (10.93) & (11.37) \\
\hline \multirow[t]{2}{*}{ detector } & -20.97 & -27.39 & -47.24 & -69.22 \\
\hline & $(0.80)$ & $(3.71)$ & $(10.84)$ & $(30.88)$ \\
\hline \multirow[t]{2}{*}{ hour1:detector } & 2.15 & -7.25 & & \\
\hline & $(0.95)$ & $(4.22)$ & & \\
\hline \multirow[t]{2}{*}{ hour2:detector } & 0.71 & -10.06 & & \\
\hline & $(0.93)$ & $(4.46)$ & & \\
\hline \multirow[t]{2}{*}{ hour3:detector } & -0.19 & -4.83 & & \\
\hline & $(0.99)$ & $(4.27)$ & & \\
\hline \multirow[t]{2}{*}{ hour4:detector } & -0.86 & -2.41 & & \\
\hline & $(1.01)$ & $(4.64)$ & & \\
\hline \multirow[t]{2}{*}{ hour5:detector } & 1.08 & -8.74 & & \\
\hline & $(1.02)$ & $(4.74)$ & & \\
\hline \multirow[t]{2}{*}{ hour6:detector } & 1.46 & -7.46 & & \\
\hline & $(0.98)$ & $(4.68)$ & & \\
\hline \multirow[t]{2}{*}{ hour7:detector } & 3.66 & -12.07 & & \\
\hline & $(1.02)$ & $(4.35)$ & & \\
\hline \multirow[t]{2}{*}{ hour8:detector } & 3.35 & -16.05 & & \\
\hline & $(0.99)$ & $(4.41)$ & & \\
\hline \multirow[t]{2}{*}{ hour9:detector } & 5.25 & -2.59 & & \\
\hline & $(0.97)$ & $(3.85)$ & & \\
\hline \multirow[t]{2}{*}{ hour10:detector } & 5.99 & -1.60 & & \\
\hline & $(0.95)$ & $(3.81)$ & & \\
\hline \multirow[t]{2}{*}{ hour11:detector } & 2.46 & -5.78 & & \\
\hline & $(0.90)$ & $(3.64)$ & & \\
\hline \multirow[t]{2}{*}{ hour12:detector } & 3.66 & 1.77 & & \\
\hline & $(0.94)$ & $(3.63)$ & & \\
\hline
\end{tabular}


All Fires Kitchen Living Room Bedroom

\begin{tabular}{ccc}
\hline hour13:detector & 3.61 & -6.83 \\
& $(0.87)$ & $(3.61)$ \\
hour14:detector & 5.46 & 0.63 \\
& $(0.90)$ & $(3.56)$ \\
hour15:detector & 4.16 & -4.54 \\
& $(0.85)$ & $(3.54)$ \\
hour16:detector & 2.82 & 1.92 \\
& $(0.86)$ & $(3.54)$ \\
hour17:detector & 0.79 & -0.86 \\
& $(0.88)$ & $(3.40)$ \\
hour18:detector & 1.65 & -5.07 \\
& $(0.87)$ & $(3.54)$ \\
hour19:detector & 0.22 & -3.56 \\
& $(0.88)$ & $(3.58)$ \\
hour20:detector & -2.68 & -6.38 \\
& $(0.87)$ & $(3.62)$ \\
hour21:detector & -1.75 & -5.73 \\
& $(0.87)$ & $(3.64)$ \\
hour22:detector & -0.24 & -10.56 \\
& $(0.89)$ & $(3.89)$ \\
hour23:detector & -1.34 & -1.41 \\
& $(0.94)$ & $(4.06)$ \\
Number of Observations & 523791 & 112411 \\
*** $<<0.001 ; *$ p $<0.01 ;{ }^{*} \mathrm{p}<0.05$ & &
\end{tabular}



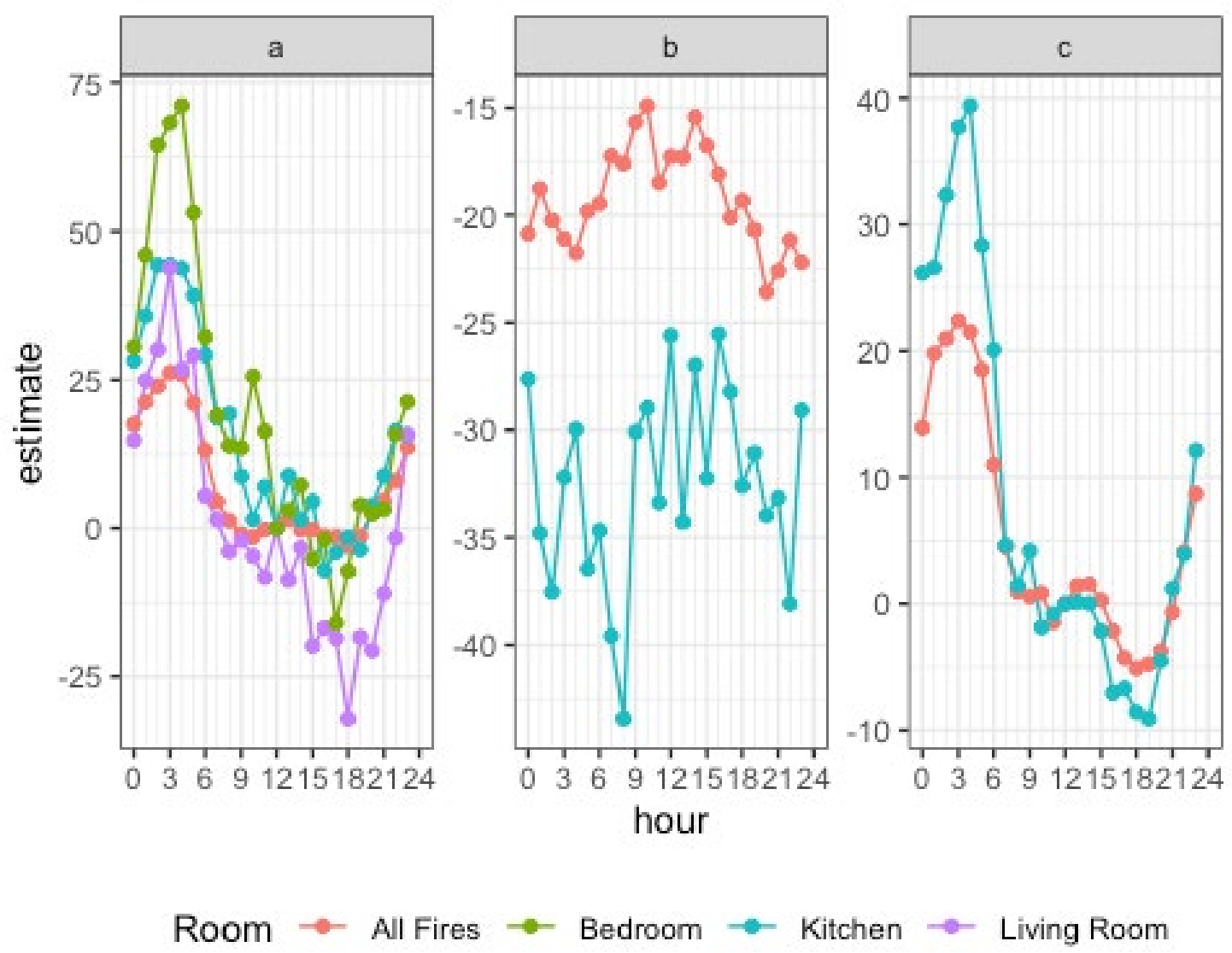

Fig. 5: Reporting time offsets in minutes by time of day and room of fire origin. Left shows offsets without smoke alarms. Right shows the improvement smoke alarms bring.

The report time offsets shown in Fig. 5 all follow a similar pattern. Generally, there is a daytime pattern, where the impact of travel time is similar, a night-time pattern, and some transition period. The night-time offsets are positive, meaning that response time is significantly longer at night than during the day. There are two polar interpretations of the transition period. The first interpretation is that for any house, during the transition period the impact of travel time lies between that for the night time period and that of the daytime period. The second interpretation is that for any house there are only two patterns for the impact of travel time: a daytime and a nighttime one. The transition period occurs because different houses transition between the two patterns at different times. It seems likely that the latter interpretation is closer to being the correct one.

Fig. 5.b shows the change in reporting times that the addition of smoke alarms provides by time of day for all fires and for kitchen fires. (Time-of-day offsets for smoke alarms could not be estimated for living-room and bedroom fires.) For all fires, on average, smoke alarms save 21 minutes. That varies by time of day, where (as expected) the savings is greater at night. The pattern for kitchen fires is similar; however, the average savings for kitchen fires is greater than for all fires. 
Fig. 5.c shows the offsets by time of day for the case where smoke alarms are present. Since time-of-day offsets for smoke alarms could not be estimated for living-room and bedroom fires those are not included. As with Fig. 5c since the time-of-day offsets are only defined up to an additive constant, they have been adjusted in the figure so that noon is zero

As a check on the methodology, Fig. 6 shows the probability that a fire will spread beyond the room of origin versus the delayed fire department travel time for fires where smoke alarms are present. Each line represents a different hour of the day, and the model estimate is included. The delayed travel time is calculated as the reported fire department travel time added to the estimated reporting delay. Because the probability of fire spread increases linearily with the delayed travel time, the fit of the calculate data appears to be good, supporting the model.

Table 2: Summary of the effect of time of day and smoke alarm presence on reporting delay in minutes. The baseline is daytime with smoke alarms present.

\begin{tabular}{|c|c|c|c|c|}
\hline \multirow[b]{2}{*}{ Hold Constant } & \multicolumn{2}{|c|}{ Change } & \multirow{2}{*}{$\begin{array}{l}\text { Effect } \\
\text { (mins) }\end{array}$} & \multirow{2}{*}{$\begin{array}{l}\text { Standard } \\
\text { Deviation }\end{array}$} \\
\hline & From & To & & \\
\hline Daytime & Detectors & No Detectors & 18.2 & 0.007 \\
\hline Nighttime & Detectors & No Detectors & 20.5 & 0.012 \\
\hline Detectors Present & Daytime & Nighttime & 18.5 & 0.007 \\
\hline Detectors Absent & Daytime & Nighttime & 20.9 & 0.012 \\
\hline- & Daytime with Detectors & Nighttime, No Detectors & 39.1 & 0.018 \\
\hline
\end{tabular}




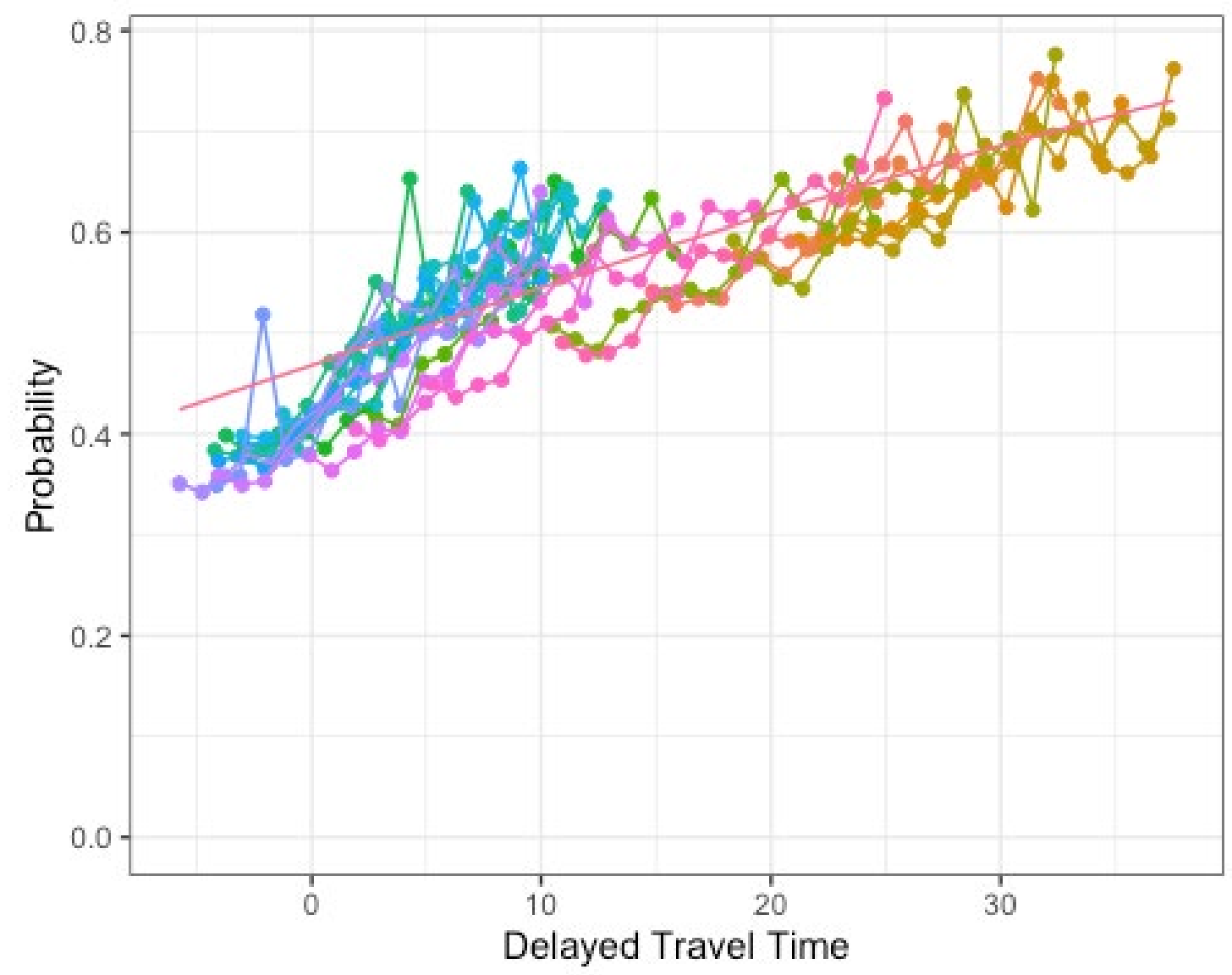

Fig. 6: Probability that a fire will spread beyond the room of origin versus delayed fire department travel time.

\section{Conclusions}

On average smoke alarms reduce reporting time by $19.2(95 \%$ confidence limits \pm 0.016$)$ minutes. Reporting time is longer at night than during the day. With no alarm, the mean reporting delay at night compared to daytime is $20.5( \pm 0.024)$ minutes and with an alarm the mean reporting delay is $18.1( \pm 0.013)$ minutes. It would be expected that the savings is greater at night than in the day because during the day people are active and moving about and therefore more likely to encounter the fire even without the alarm. That expectation is borne out by the results, with detectors saving $2.4( \pm 0.016)$ minutes more at night than during the day.

These results are on average. That is, any specific case may be less than this or more than this. For example, there will be cases where a person would have encountered the fire almost as soon as the alarm, and there will be cases where the fire would not have been detected absent the alarm until much later. Similar for the time-of-day results.

It is important to emphasize that this analysis relates to the universe of reported fires. It is well known that the vast majority of fires are never reported to the fire department. Presumably they are extinguished by the residents, or self-extinguish. That means that the characteristics of reported fires will differ in important ways from those of ignitions. Among 
other things, reported fires will most likely be more aggressive on average than unreported fires.

\section{References}

[1] Ahrens M (2019) Smoke Alarms in U.S. Home Fires (National Fire Protection Association, Quincy, Mass).

[2] Rohde D, Corcoran J, Sydes M, Higginson A (2016) The association between smoke alarm presence and injury and death rates: A systematic review and meta-analysis. Fire Safety Journal 81:58-63. https://doi.org/10.1016/i.firesaf.2016.01.008

[3] Gilbert S (2018) Estimating smoke alarm effectiveness and spatial distribution in homes. (National Institute of Standards; Technology, Gaithersburg, MD), NIST TN 2020. https://doi.org/10.6028/NIST.TN.2020

[4] Greene MA, Andres C (2009) 2004-2005 National Sample Survey of Unreported Residential Fires (US Consumer Product Safety Commission). Available at http://osfmtraining.fire.ca.gov/firelifesafety/pdf/Smoke\%20Alarm\%20Task\%20Force/R40\%20CPSC\%20-\%2020042005\%20National\%20Sample\%20Survey\%20of\%20Unreported\%20Residential\%20Fires\%20( 2).pdf

[5] Hall JR Jr. (2004) How Many People Can Be Saved from Home Fires if Given More Time to Escape? Fire Technology 40(2):117-126. https://doi.org/10.1023/B:FIRE.0000016839.11376.b3

[6] Wood PG (1972) The behavior of people in fires. (Fire Research Station), Fire Research Notes 953.

[7] Bryan JL (1977) Smoke as a determinant of human behavior in fire situations (project people). (National Institute of Standards; Technology, Gaithersburg, MD), GCR-77-94.

[8] Thompson OF, Galea ER, Hulse LM (2018) A review of the literature on human behaviour in dwelling fires. Safety Science 109:303-312. https://doi.org/10.1016/i.ssci.2018.06.016

[9] Thompson OF, Wales D (2015) A qualitative study of experiences, actions and motivations during accidental dwelling fires. Fire and Materials 39(4):453-465.

[10] Pauls J (1999) A personal perspective on research, consulting and codes/standards development in fire-related human behaviour, 1969-1999, with an emphasis on space and time factors. Fire and Materials 23(6):265-272. https://doi.org/10.1002/(SICl)10991018(199911/12)23:6<265::AID-FAM698>3.0.CO;2-O 


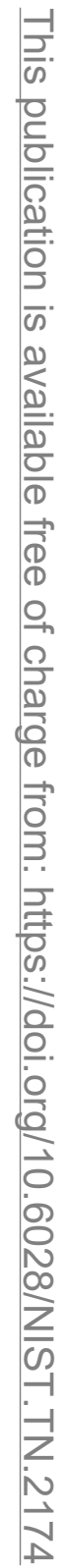




\section{Appendix A: Raw Results}

Table 3: Raw Results

All Fires Kitchen Living Room Bedroom

\begin{tabular}{|c|c|c|c|c|}
\hline alpha & $\begin{array}{c}2.69 \\
(0.31)\end{array}$ & $\begin{array}{c}2.62 \\
(1.34)\end{array}$ & $\begin{array}{c}2.58 \\
(0.76)\end{array}$ & $\begin{array}{c}2.94 \\
(0.82)\end{array}$ \\
\hline \multirow[t]{2}{*}{ travel } & 0.02 & 0.01 & 0.01 & 0.01 \\
\hline & $(0.00)$ & $(0.00)$ & $(0.00)$ & $(0.00)$ \\
\hline \multirow[t]{2}{*}{ hour0 } & 0.20 & -0.38 & 0.22 & -0.01 \\
\hline & $(0.03)$ & $(0.09)$ & $(0.08)$ & $(0.05)$ \\
\hline \multirow[t]{2}{*}{ hour1 } & 0.28 & -0.28 & 0.31 & 0.07 \\
\hline & $(0.04)$ & $(0.10)$ & $(0.09)$ & $(0.06)$ \\
\hline \multirow[t]{2}{*}{ hour2 } & 0.33 & -0.16 & 0.36 & 0.16 \\
\hline & $(0.04)$ & $(0.11)$ & $(0.09)$ & $(0.06)$ \\
\hline \multirow[t]{2}{*}{ hour3 } & 0.38 & -0.16 & 0.48 & 0.18 \\
\hline & $(0.04)$ & $(0.11)$ & $(0.10)$ & $(0.06)$ \\
\hline \multirow[t]{2}{*}{ hour4 } & 0.38 & -0.17 & 0.33 & 0.19 \\
\hline & $(0.04)$ & $(0.11)$ & $(0.09)$ & $(0.06)$ \\
\hline \multirow{2}{*}{ hour5 } & 0.28 & -0.23 & 0.35 & 0.10 \\
\hline & $(0.04)$ & $(0.11)$ & $(0.09)$ & $(0.06)$ \\
\hline \multirow[t]{2}{*}{ hour6 } & 0.11 & -0.36 & 0.14 & -0.00 \\
\hline & $(0.03)$ & $(0.10)$ & $(0.08)$ & $(0.06)$ \\
\hline \multirow[t]{2}{*}{ hour7 } & -0.07 & -0.50 & 0.11 & -0.07 \\
\hline & $(0.03)$ & $(0.09)$ & $(0.08)$ & $(0.05)$ \\
\hline \multirow[t]{2}{*}{ hour8 } & -0.13 & -0.49 & 0.06 & -0.10 \\
\hline & $(0.03)$ & $(0.09)$ & $(0.08)$ & $(0.05)$ \\
\hline \multirow[t]{2}{*}{ hour9 } & -0.18 & -0.63 & 0.08 & -0.10 \\
\hline & $(0.02)$ & $(0.08)$ & $(0.08)$ & $(0.05)$ \\
\hline \multirow[t]{2}{*}{ hour10 } & -0.19 & -0.73 & 0.05 & -0.03 \\
\hline & $(0.02)$ & $(0.08)$ & $(0.08)$ & $(0.05)$ \\
\hline \multirow[t]{2}{*}{ hour11 } & -0.16 & -0.66 & 0.02 & -0.08 \\
\hline & $(0.02)$ & $(0.08)$ & $(0.08)$ & $(0.05)$ \\
\hline \multirow[t]{2}{*}{ hour12 } & -0.16 & -0.75 & 0.09 & -0.16 \\
\hline & $(0.02)$ & $(0.07)$ & $(0.08)$ & $(0.05)$ \\
\hline \multirow[t]{2}{*}{ hour13 } & -0.13 & -0.63 & 0.02 & -0.15 \\
\hline & $(0.02)$ & $(0.08)$ & $(0.08)$ & $(0.05)$ \\
\hline \multirow[t]{2}{*}{ hour14 } & -0.17 & -0.73 & 0.07 & -0.13 \\
\hline & $(0.02)$ & $(0.07)$ & $(0.08)$ & $(0.05)$ \\
\hline \multirow[t]{2}{*}{ hour15 } & -0.16 & -0.69 & -0.08 & -0.19 \\
\hline & $(0.02)$ & $(0.08)$ & $(0.07)$ & $(0.05)$ \\
\hline \multirow[t]{2}{*}{ hour16 } & -0.19 & -0.84 & -0.05 & -0.17 \\
\hline & $(0.02)$ & $(0.07)$ & $(0.07)$ & $(0.05)$ \\
\hline
\end{tabular}


All Fires Kitchen Living Room Bedroom

\begin{tabular}{|c|c|c|c|c|}
\hline hour17 & $\begin{array}{l}-0.19 \\
(0.02)\end{array}$ & $\begin{array}{c}-0.80 \\
(0.07)\end{array}$ & $\begin{array}{c}-0.07 \\
(0.07)\end{array}$ & $\begin{array}{c}-0.24 \\
(0.05)\end{array}$ \\
\hline hour18 & $\begin{array}{c}-0.22 \\
(0.02)\end{array}$ & $\begin{array}{c}-0.77 \\
(0.07)\end{array}$ & $\begin{array}{c}-0.19 \\
(0.07)\end{array}$ & $\begin{array}{c}-0.20 \\
(0.05)\end{array}$ \\
\hline hour19 & $\begin{array}{l}-0.19 \\
(0.02)\end{array}$ & $\begin{array}{c}-0.80 \\
(0.07)\end{array}$ & $\begin{array}{l}-0.07 \\
(0.07)\end{array}$ & $\begin{array}{c}-0.14 \\
(0.05)\end{array}$ \\
\hline hour20 & $\begin{array}{l}-0.11 \\
(0.03)\end{array}$ & $\begin{array}{l}-0.70 \\
(0.08)\end{array}$ & $\begin{array}{c}-0.09 \\
(0.07)\end{array}$ & $\begin{array}{l}-0.15 \\
(0.05)\end{array}$ \\
\hline hour21 & $\begin{array}{l}-0.06 \\
(0.03)\end{array}$ & $\begin{array}{c}-0.63 \\
(0.08)\end{array}$ & $\begin{array}{c}-0.00 \\
(0.07)\end{array}$ & $\begin{array}{l}-0.15 \\
(0.05)\end{array}$ \\
\hline hour22 & $\begin{array}{c}0.01 \\
(0.03)\end{array}$ & $\begin{array}{c}-0.53 \\
(0.08)\end{array}$ & $\begin{array}{c}0.08 \\
(0.08)\end{array}$ & $\begin{array}{c}-0.08 \\
(0.05)\end{array}$ \\
\hline hour23 & $\begin{array}{c}0.12 \\
(0.03)\end{array}$ & $\begin{array}{c}-0.54 \\
(0.09)\end{array}$ & $\begin{array}{c}0.23 \\
(0.08)\end{array}$ & $\begin{array}{c}-0.06 \\
(0.05)\end{array}$ \\
\hline detector & $\begin{array}{l}-0.43 \\
(0.02)\end{array}$ & $\begin{array}{c}-0.37 \\
(0.04)\end{array}$ & $\begin{array}{l}-0.41 \\
(0.02)\end{array}$ & $\begin{array}{c}-0.34 \\
(0.01)\end{array}$ \\
\hline hour1:detector & $\begin{array}{c}0.04 \\
(0.02)\end{array}$ & $\begin{array}{l}-0.10 \\
(0.06)\end{array}$ & & \\
\hline hour2:detector & $\begin{array}{c}0.01 \\
(0.02)\end{array}$ & $\begin{array}{c}-0.13 \\
(0.06)\end{array}$ & & \\
\hline hour3:detector & $\begin{array}{l}-0.00 \\
(0.02)\end{array}$ & $\begin{array}{l}-0.06 \\
(0.06)\end{array}$ & & \\
\hline hour4:detector & $\begin{array}{l}-0.02 \\
(0.02)\end{array}$ & $\begin{array}{c}-0.03 \\
(0.06)\end{array}$ & & \\
\hline hour5:detector & $\begin{array}{c}0.02 \\
(0.02)\end{array}$ & $\begin{array}{l}-0.12 \\
(0.06)\end{array}$ & & \\
\hline hour6:detector & $\begin{array}{c}0.03 \\
(0.02)\end{array}$ & $\begin{array}{l}-0.10 \\
(0.06)\end{array}$ & & \\
\hline hour7:detector & $\begin{array}{c}0.08 \\
(0.02)\end{array}$ & $\begin{array}{c}-0.16 \\
(0.06)\end{array}$ & & \\
\hline hour8:detector & $\begin{array}{c}0.07 \\
(0.02)\end{array}$ & $\begin{array}{l}-0.21 \\
(0.05)\end{array}$ & & \\
\hline hour9:detector & $\begin{array}{c}0.11 \\
(0.02)\end{array}$ & $\begin{array}{c}-0.03 \\
(0.05)\end{array}$ & & \\
\hline hour10:detector & $\begin{array}{c}0.12 \\
(0.02)\end{array}$ & $\begin{array}{l}-0.02 \\
(0.05)\end{array}$ & & \\
\hline hour11:detector & $\begin{array}{c}0.05 \\
(0.02)\end{array}$ & $\begin{array}{c}-0.08 \\
(0.05)\end{array}$ & & \\
\hline hour12:detector & $\begin{array}{c}0.07 \\
(0.02)\end{array}$ & $\begin{array}{c}0.02 \\
(0.05)\end{array}$ & & \\
\hline hour13:detector & 0.07 & -0.09 & & \\
\hline
\end{tabular}




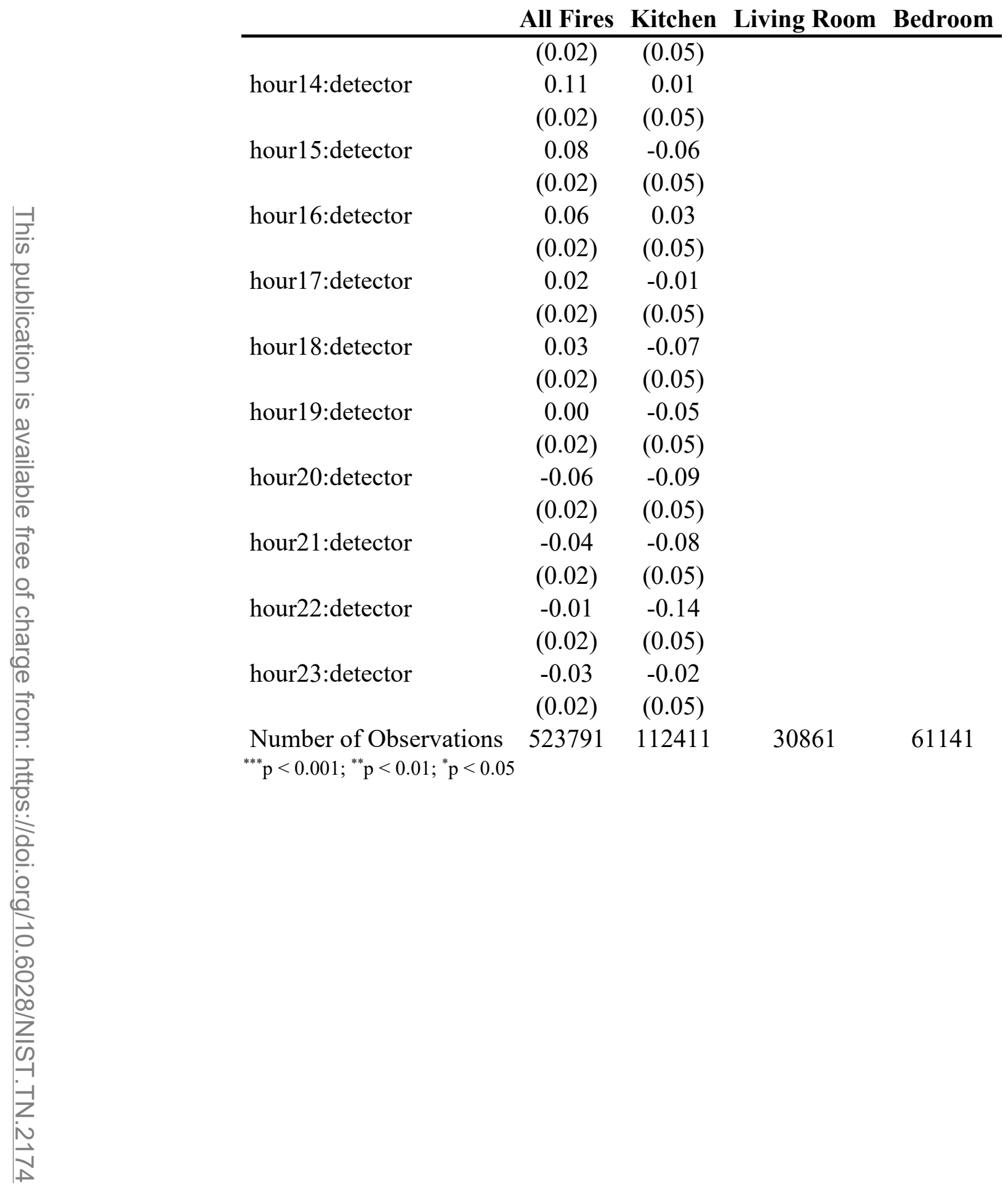




\section{Appendix B: Abstract Model}

The abstract model is described more formally and rigorously below.

Let $X$ represent the space of measured factors affecting detection time.

Let $\mathcal{G}$ be the set of fire growth curves. Fires are monotonic functions of $\mathcal{J}$ (time) starting at zero and not exceeding 1.

$r$ lies between zero and one and represents the size of the fire at which it goes beyond the room of origin.

$\mathcal{P}$ is the set of people, where for any $p \in \mathcal{P}$, there is an associated fire size $s_{p}$. If at the time of detection, the size of the fire is greater than $s_{p}$ it is reported to the fire department. If the fire is smaller than $s_{p}$ at the time of detection, it is extinguished without reporting to the fire department. Note that there may be people for whom $s_{p}=0$. Often, we will identify reporting size, $s_{p}$, with person.

$\mathcal{D}$ is a set of detection functions, which map $X$ to detection time $t_{d} \in \mathcal{T}$, and reporting time $t_{r} \in \mathcal{T}$. If at the time of detection $t_{d}$ the fire size $G\left(t_{d}\right) \leq s_{p}$ then the fire is extinguished without reporting to the fire department. If at the time of detection, $t_{d}$, the fire size $G\left(t_{d}\right)>$ $s_{p}$, then the fire is reported to the fire department after a delay of $t_{r}$.

Note that $\mathcal{D}, \mathcal{P}$, and $\mathcal{G}$ are part of probability spaces that are left implicit.

The space of fires is the product space of $\mathcal{X}, \mathcal{D}, \mathcal{P}$, and $\mathcal{G}$. A fire is a set of characteristics, $x \in \mathcal{X}$, a fire growth curve $g \in \mathcal{G}$, detection function $d \in \mathcal{D}$, and a person $p \in \mathcal{P}$.

There are two factors that can impact reported fire size when some factor in $X$ causes a delay in reporting time: detection time and reporting delay. The impact of reporting delay is straightforward. The set of fires reported to the fire department are unchanged. The only impact of reporting delay is to allow the same fires to grow larger. In that sense, reporting delay is directly comparable to response time.

Next consider the impact of detection time. Start by holding detection function, $d$, and person, $s_{p}$, constant. The two detection times divide growth curves into three sets: $G_{r}$, the set of fires that are reported at either detection time, $G_{x}$, the set of fires that are extinguished at either detection time, and $G_{m}$, the set of fires that are extiguished at the earlier detection time and reported at the later time. (Note that the reporting time has no impact on this analysis). The set of fires in $G_{x}$ have no impact on the analysis. The impact of the set of fires in $G_{r}$ is unambiguous: the fires are larger when they are reported, and more of them will have spread beyond the room of origin by the time the fire department arrives.

The impact of the fires in $G_{m}$ is more ambiguous and depends on their growth rate compared to the fires in $G_{r}$. They started out smaller than the fires in $G_{r}$. It is natural to expect that on average they will continue to be smaller than the fires in $G_{r}$. However, it possible to construct a case where that does not hold. Suppose all fires come in two types. A fast type that grows rapidly but quickly reach a maximum size (e.g., a rapidly burning fuel without enough energy content to flash over a room), and a slow type that grows slowly but that eventually 
grows to be large (e.g., an initially slow-burning fuel that will eventually release enough heat to flash over a room). In that case, a detection delay could very well result an increase in the average size of fire when the fire department arrives. In this case, estimating the detection delay by matching time impacts of that delay to the impacts of fire-department response time will overestimate the actual delay.

The more natural case is where fires that start out smaller remain smaller. For example, installation of smoke alarms tends to result in the extinguishment of the less aggressive (and less dangerous) fires. In this case the impact of detection delay will be less than the impact of a delay in fire-department response time. So, estimating the detection delay by matching time impacts of that delay to the impacts of fire-department response time will underestimate the actual delay.

It is possible to construct a case where reporting delay actually reduces the average size of fires. Again, consider two types of fires: fast-growing fires that grow to be large, and slow growing fires that eventually exceed the reporting size and then go out. If the second group of fires significantly outnumber the first group, then the average size of fires could decrease with increased reporting time. Note that this does not mean the delay is good. For any individual fire delay means it becomes larger, does more damage, and potentially causes more casualties. However, delay means that the initial group of large fire sizes are diluted by a larger group of smaller fire sizes. We will assume that this case does not occur.

The above analysis held person and detection function constant. Since detection function determines when the fire is detected, its analysis is exactly parallel to the analysis above.

Person affects how severe a fire must be before it is reported. So long as the average fire size for each person increases with increasing reporting time then averaging over persons doesn't change that result.

It is tempting to make $\mathcal{D}$ dependent on fire. After all, in real life detection will in some cases depend on fire size. However, that complicates the analysis significantly. Even worse (and more realistic) would be to make detection dependent on the growth rate of the fire. Here think about a smoke alarm whose detection probability depends on HRR. The problem with either of these is that without some strong assumptions (which we are not sure how to specify) anything could happen. This is the realistic case, and those assumptions do apply, but we are not sure what they are and therefore cannot analyze them. 


\section{Appendix C: Maximum Likelihood Model}

What follows is the mathematical development of the maximum likelihood model.

As before, we let:

$$
\mathrm{P}\left\{y_{i}=1\right\}=\alpha F\left(u\left(x_{i}, \beta\right)\right)=\alpha F\left(u_{i}\right)
$$

Then the log-likelihood function is:

$$
L=\sum_{\left\{i \mid y_{i}=1\right\}} w_{i} \ln \left(\alpha F\left(u_{i}\right)\right)+\sum_{\left\{i \mid y_{i}=0\right\}} w_{i} \ln \left(1-\alpha F\left(u_{i}\right)\right)
$$

or

$$
L=\sum_{i} w_{i}\left[y_{i} \ln \left(\alpha F\left(u_{i}\right)\right)+\left(1-y_{i}\right) \ln \left(1-\alpha F\left(u_{i}\right)\right)\right]
$$

where we are including weights.

The derivative (gradient) of $\mathrm{L}$ is (notice the simplification of the notation):

$$
\frac{d L}{d \beta}=\sum_{i} w_{i}\left[\begin{array}{c}
y_{i} \frac{F_{i}}{\alpha F_{i}}+\frac{-\left(1-y_{i}\right) F_{i}}{1-\alpha F_{i}} \\
{\left[\begin{array}{c}
\alpha \frac{\alpha f_{i}}{\alpha F_{i}}+\frac{-\left(1-y_{i}\right) \alpha f_{i}}{1-\alpha F_{i}}
\end{array}\right] \frac{d u_{i}}{d \beta}}
\end{array}\right]=\sum_{i} w_{i}\left[\begin{array}{c}
\frac{y_{i}-\alpha F_{i}}{\alpha\left(1-\alpha F_{i}\right)} \\
{\left[\begin{array}{c}
f_{i}\left(y_{i}-\alpha F_{i}\right) \\
F_{i}\left(1-\alpha F_{i}\right)
\end{array}\right] \frac{d u_{i}}{d \beta}}
\end{array}\right]
$$

The Hessian is:

$$
\frac{d^{2} L}{d \beta^{2}}=\sum_{i} w_{i}\left[\begin{array}{cc}
-\left[\frac{y_{i}-\alpha F_{i}}{\alpha\left(1-\alpha F_{i}\right)}\right]^{2} & -\frac{\left(1-y_{i}\right) f_{i}}{\left(1-\alpha F_{i}\right)^{2}} \frac{d u_{i}}{d \beta^{\prime}} \\
-\frac{\left(1-y_{i}\right) f_{i}}{\left(1-\alpha F_{i}\right)^{2}} \frac{d u_{i}}{d \beta} & \frac{d L}{d u_{i}} \frac{d^{2} u_{i}}{d \beta d \beta^{\prime}}+\frac{d^{2} L}{d u_{i}^{2}} \frac{d u_{i}}{d \beta} \frac{d u_{i}}{d \beta^{\prime}}
\end{array}\right]
$$

where

$$
\frac{d L}{d u_{i}}=\frac{f_{i}\left(y_{i}-\alpha F_{i}\right)}{F_{i}\left(1-\alpha F_{i}\right)}
$$

and

$$
\frac{d^{2} L}{d u_{i}^{2}}=\left(F_{i} f_{i}^{\prime}-f_{i}^{2}\right)\left[\frac{y_{i}-\alpha F_{i}}{F_{i}\left(1-\alpha F_{i}\right)}\right]^{2}-\left(1-y_{i}\right) \frac{\alpha f_{i}^{\prime}}{\left(1-\alpha F_{i}\right)^{2}}
$$




\section{Appendix D: Smoke Alarms and Time of Day}

Fig. 7 shows the percent of fires with smoke alarms present by time of day. In addition, the scaled number of fires where alarm presence was unknown is included as reference. The data used in the figure includes departments with more than 500 reported home fires (to ensure that there is a 'large' sample for each department), and with at least a $75 \%$ reporting rate on smoke alarm presence at fires. Detroit is explicitly excluded because it is expected to be different.

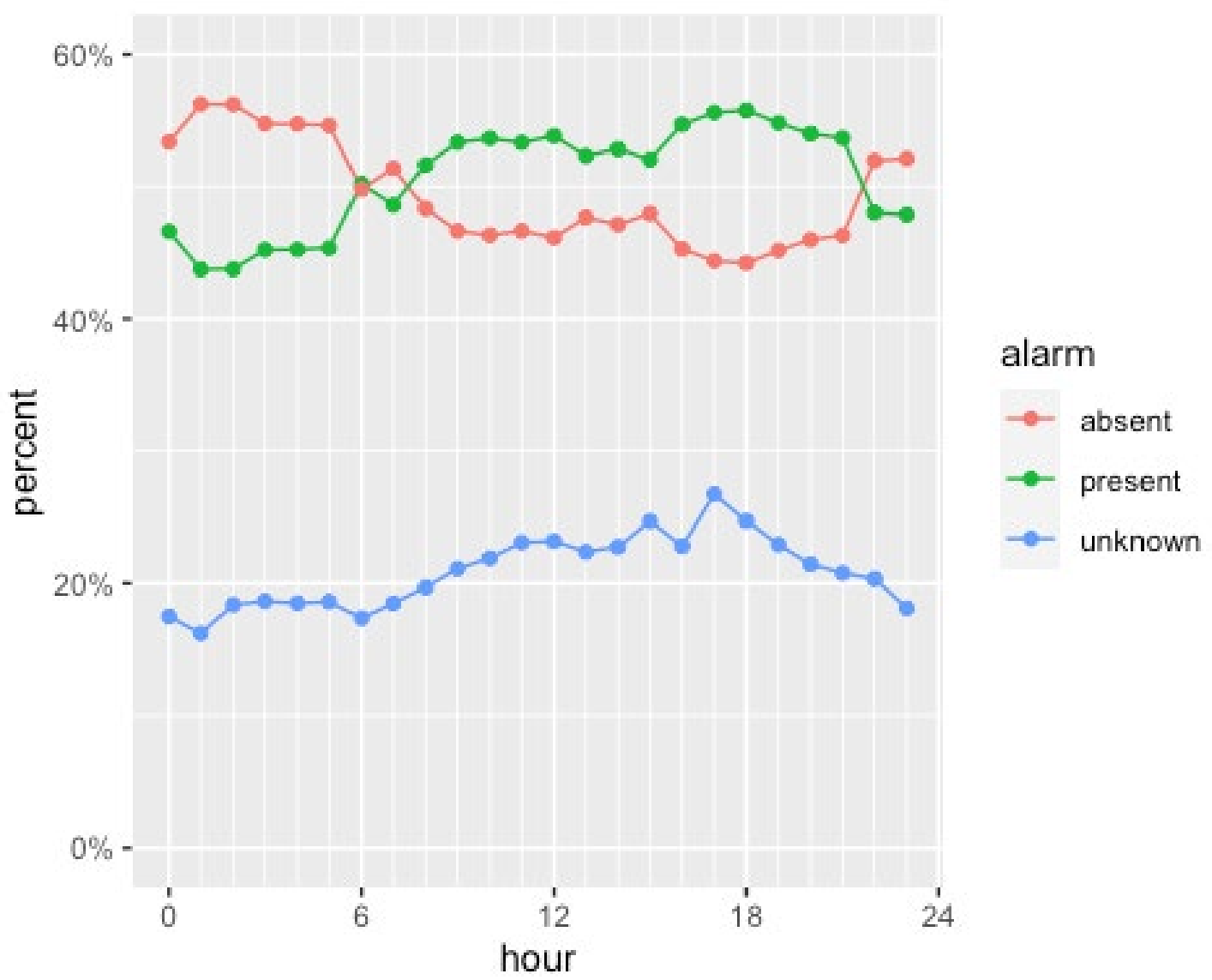

Fig. 7: Reporting rate for smoke alarms at fires by time of day.

As can be seen in Fig. 7, the proportion of reported fires in homes with no smoke alarms varies by time of day, with the proportion of home fires where there are no smoke alarms increasing at night. That makes sense (and was expected) because detection is harder at night, since people are more likely to be asleep. Smoke alarms should significantly shorten detection time at night, and by a larger amount than during the day when people are more likely to be moving around and more likely to detect a fire independently of the smoke alarm.

It is also clear from the figure that reporting rate depends on time of day, with an obvious inverse relationship with how busy the department is. That is, alarm presence is more likely to be reported during time periods when there are relatively few reported fires and less likely to be reported during periods when there are relatively many reported fires. Right now, this is not accounted for. 


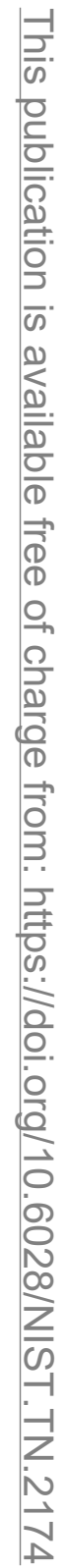

